Article

\title{
Rapid PCR Method for the Selection of 1,3-Pentadiene Non-Producing Debaryomyces hansenii Yeast Strains
}

\author{
Eva-María Rivas ${ }^{1,2, \dagger}$, Petra Wrent ${ }^{1,2,+}$ and María-Isabel de Silóniz ${ }^{1,2, * \text { (D) }}$ \\ 1 Department of Genetics, Physiology and Microbiology. Biological Sciences Faculty. Complutense University \\ of Madrid. José Antonio Nováis, 12. 28040 Madrid, Spain; evarifer@gmail.com (E.-M.R.); \\ pwrent@ucm.es (P.W.) \\ 2 CEI Campus Moncloa, UCM-UPM, 28040 Madrid, Spain \\ * Correspondence: siloniz@bio.ucm.es; Tel.: +34-91-3944962 \\ + These authors contributed equally to this work.
}

Received: 17 December 2019; Accepted: 28 January 2020; Published: 7 February 2020

\begin{abstract}
To prevent microbial growth and its consequences, preservatives such as sorbic acid or its salts, commonly known as sorbates, are added to foods. However, some moulds and yeasts are capable of decarboxylating sorbates and producing 1,3-pentadiene. This is a volatile compound with an unpleasant "petroleum-like "odour, which causes consumer rejection of the contaminated products. In this work, we studied the production of 1,3-pentadiene in 91 strains of the yeast Debaryomyces hansenii, and we found that nearly $96 \%$ were able to produce this compound. The sequence of the FDC1Dh gene was analysed showing differences between 1,3-pentadiene producer $(\mathrm{P})$ and non-producer (NP) strains. A specific PCR assay with degenerated primers based on the gene sequence was developed to discern NP and P strains. It was tested on D. hansenii strains and on some physiologically related species frequently isolated from foods, such as D. fabrii, D. subglobosus and Meyerozyma guillermondii. This method could be applied for the selection of NP D. hansenii strains, useful in biotechnological food production and as a biocontrol agent.
\end{abstract}

Keywords: strains-selection; 1,3-pentadiene; sorbate; spoilage-yeast; food-preservation

\section{Introduction}

Yeasts are beneficial organisms that contribute to the production of certain foods and beverages [1-4] but can cause spoilage [5,6]. There is an increased concern about the spoilage produced by yeasts [7]. They are able to grow in products with low water activity, $\mathrm{pH}$, and low temperatures [7]. Moreover, few species are able to grow in the presence of preservatives such as low molecular weight weak acids $[5,8]$.

Sorbic acids and their salts are weak acid preservatives whose fungistatic activities are favoured at low $\mathrm{pH}$, where they are found in their undissociated forms. The FDA (U.S. Food and Drug Administration), JEDFA (Joint FAO/WHO Expert Committee on Food Additives) and SCF (Scientific Committee in Food) evaluations consider these preservatives to be among the safest and, according to the EU EFSA Panel, the most effective. However, the microbial decarboxylation of sorbates in a single step produces volatile 1,3-pentadiene that has a petroleum-hydrocarbon-like unpleasant off-odour. Fungal sorbate degradation was first demonstrated on Penicillium strains isolated from cheddar cheese, all the strains isolated were able to eliminate the sorbic acid [9]. Later in the 1990s, more yeast strains were described as 1,3-pentadiene producers, including D. hansenii strains, which were isolated from cheese, margarine, butter or marzipan [10-13]. D. hansenii appears in the inventory of microorganisms with technological benefits for its use in food fermentation [1-3,14]. It is also used in cured meat, where it has been proposed as a starter $[15,16]$ and as a biocontrol agent [17-20]. D. hansenii's effectiveness as 
a biocontrol agent is well studied but its ability to degrade sorbates if strains survey and remain in the final product has not been analysed. Therefore, a method that distinguishes between 1,3-pentadiene producer $(\mathrm{P})$ or non-producer strains $(\mathrm{NP})$ could be of great interest to the industry.

Detection of 1,3-pentadiene is feasible by sensorial, gas chromatography coupled to mass spectrometry (GC-MS) or MWIR (Mid-Wave IR) devices [11,21-24]. These techniques and their implementation are time-consuming and expensive for 1,3-pentadiene detection.

The decarboxylation of sorbic acid in 1,3-pentadiene requires the removal of the carboxyl group of the molecule. The molecular basis of 1,3-pentadiene production has been studied mainly in strains of Aspegillus niger and Saccharomyces cerevisiae $[25,26]$ and it was shown that it requires the activity of a Pad1 enzyme (named in this work as Phenylacrylic Acid Decarboxylase). Goodney y Tubb [27] described that the PAD1 gene (named in this work as POF1, Fenolic Off Flavour) encoded for a ferulic acid decarboxylase. Sorbic acid is not considered a phenylacrylic acid as ferulic, cumaric or cinnamic acids but shares some structural characteristics with them, such as a carboxylic group and an aliphatic chain with two double bonds. Further studies in Aspergillus reported that a second gene was involved [28]. It is an oxidative decarboxylation produced by two enzyme systems: PAD1 and FDC1 (Ferulic Acid Decarboxylase) [29]. More recently, a positive relation has been reported between the number of single nucleotide polymorphisms of PAD1 and FDC1 and ferulic acid decarboxylation in several industrial yeast strains [30]. The aim of this work was to develop a simple method for $D$. hansenii NP strains selection using a new PCR protocol based on the FDC1Dh gene.

\section{Materials and Methods}

\subsection{Yeast Strains and Culture Conditions}

A total of 129 strains, some of them from 1,3-pentadiene spoiled foods, were used in this work from different Culture Collections or isolated in our laboratory (see Supplementary Material, Table S1). Strains were cultured at $28{ }^{\circ} \mathrm{C}$ in Yeast Morphology Broth (YMB) and routinely maintained on the same culture medium plus Agar (YMA): $0.5 \%$ (w/v) yeast extract (Difco Laboratories, Detroit, MI, USA), 0.3\% (w/v) proteose-peptone No.3 (Difco), 0.3\% (w/v) malt extract (Difco), 1\% (w/v) glucose (Panreac Quimica S.A., Barcelona, Spain), and 2\% (w/v) agar.

For 1,3-pentadiene detection, bottles $(20 \mathrm{~mL}$ chromatographic magnetic screw-capped, LLG Labware, Meckenheim, Germany) containing $9 \mathrm{~mL}$ of $\mathrm{YMB} \mathrm{pH} 7$ supplemented with potassium sorbate $0.75 \mathrm{~g} / \mathrm{L}$ (Scharlau, Barcelona, Spain) [24] were inoculated with $1 \mathrm{~mL}$ of a saline solution suspension of the yeasts (ca 6 McFarland). The bottles were incubated at $28^{\circ} \mathrm{C}$ for 4 days.

\subsection{1,3-Pentadiene Detection}

Two methods were used for 1,3-pentadiene detection. (1) GC-MS (GC:Varian CP-3800) coupled with Mass Spectrometry (MS:Saturno 2200 GC/MS/MS in automatic mode and with an automatic CombiPal Splitless injector: Two hundred microliters of headspace volatile compounds were analysed. Pure 1,3-pentadiene was used as an internal standard (50\% mixture cis-trans isomers, Aldrich-Chemical, Wisconsin, USA). (2) A sensory method: Three independent experts introduced a needle into the headspace of each culture and sniffed the sample to detect the "petroleum smell" as previously described [24]. Once the accuracy of the sensory method was verified, it was applied to the rest of the strains listed in Table 1. 
Table 1. 1,3-pentadiene detection in strains of selected species using the sensory method [24] and chromatography (GC/MS) assays.

\begin{tabular}{cccc}
\hline Species & Strains & Sensorial Detection & GC/MS \\
\hline D. hansenii & CECT 11369 & + & + \\
& Es 4 & + & + \\
& J-12 & - & - \\
DR fabryi & PR & - & - \\
& CECT $11370^{\mathrm{T}}$ & + & + \\
Z. rouxii & PR 66 & + & + \\
& T2R & + & + \\
& Bch & + & - \\
SYN 1.3 & - & + \\
& CYC 1484 & - & - \\
& BY 4747 & + & + \\
& Y05833 $(\triangle \mathrm{PAD} 1)$ & - & - \\
\hline
\end{tabular}

ATCC: American Type Culture Collection; CECT: Colección Española de Cultivos; T: Type strain.

\subsection{Primer Design and Sequencing}

For the primer design, we used the putative homologous FDC1 Saccharomyces cerevisiae region (1500 bp) [29,30] present in D. hansenii as a target, whose sequence was obtained from NCBI GenBank accession No. XM_461563.1 [31]. Based on the nucleotide sequence found in both species, the primers FDC1_Dh_Full_Fw 5' CTATTTATATCCGTACGCAGACC 3' and FDC1_Dh_Full_Rv 5' TAATATGAGCAATTTAAGACCAGAG $3^{\prime}$ were designed. With the objective of analysing differences in sequence between the 1,3-pentadiene $D$. hansenii producing $(\mathrm{P})$ or non-producing strains (NP), a DNA template was obtained as described by Lõoke et al. [32]. PCR amplifications were performed in an Eppendorf Mastercycler Gradient (Eppendorf, Hamburg, Germany) following the protocol described below. After purification (Ultraclean ${ }^{\mathrm{TM}}$ PCR clean-up Kit (MO-BIO, Larsband, USA), $80 \mu \mathrm{L}$ of all positive amplicons were sequenced (ABI PRISM 3730XL DNA Analyzer (Applied Biosystem, Foster, CA, USA). All sequences were aligned with ApE (A plasmid Editor, M.W. Davis) which is freely available [33]. After detecting the differences in the sequence between (P) and (NP), a degenerate primer FDC1_Dh_Pentadien 5'CGTAGACCYTTCTCATAATAGCA 3', where $Y=C$ or $T$ was designed to amplify a $130 \mathrm{bp}$ intermediate region which was used together with the reverse primer FDC1_Dh_Full_Rv in the PCR reaction described below. The primers used were prepared by Conda Labs-Spain Portal at Integrated DNA Technologies. For validation purposes, each strain was tested at least twice.

\subsection{PCR Conditions}

DNA amplifications were carried out in $25 \mu \mathrm{L}$ reactions containing 50-100 ng genomic DNA, $1.25 \mu \mathrm{L}$ of each primer $(20 \mu \mathrm{M}), 12.5 \mu \mathrm{L}$ NZYtaq2x colourless Mastermix (NzyTech, Lisbon, Portugal) and nuclease-free water to a final volume of $25 \mu \mathrm{L}$. Different annealing temperatures were tested, ranging from $52^{\circ} \mathrm{C}$ to $68^{\circ} \mathrm{C}$. PCR conditions were as follows: initial denaturation at $94^{\circ} \mathrm{C}$ for $5 \mathrm{~min} ; 30$ cycles of $94{ }^{\circ} \mathrm{C}$ for $1 \mathrm{~min}, 45 \mathrm{sec}$ at the $\mathrm{T}_{\mathrm{m}}$ selected, $72{ }^{\circ} \mathrm{C}$ for $45 \mathrm{sec}$; and then $1 \mathrm{cycle}$ of $72{ }^{\circ} \mathrm{C}$ for 8 min. PCR-amplified DNA fragments were separated in $1 \%(\mathrm{w} / \mathrm{v})$ agarose gels (Bio-Rad) and visualised under UV light. The GeneRuler 100bp plus DNA Ladder (MBI Fermentas) was used as a molecular size marker.

\subsection{Analysis of Protein Sequences}

The sequences of the FDC1Dh of D. hansenii were converted into their corresponding amino acid sequence with the ApE programme, taking into account that the CUG codon of D. hansenii codes for 
serine instead of leucine. Subsequently, these proteins were aligned using MegAlign-CLUSTAL method, (Lasergene, Madison, WI, USA) and web Clustal Omega [34] and Esprit 3.x [35] web applications.

\section{Results}

The ability to produce 1,3-pentadiene, indicating sorbate degradation, was studied in selected species (Table 1). The results obtained by gas chromatography coupled with mass spectrometry (GC-MS) were compared to a sensorial method [24] based on Casas et al. [36]. In the chromatographic analysis, the same peak was obtained both in the gas collected in the free headspace of the cultures and in the control samples containing 1,3-pentadiene. The fragmentation of the mass spectrum of that peak presents characteristic ions of 39, 53 and $67 \mathrm{~m} / \mathrm{z}$ (see Supplementary Material, Figure S1). As can be seen, both GC-MS and olfactory sensorial methods provided the same results (Table 1). In the remaining strains, 1,3-pentadiene was detected using the olfactory sensorial method as described in the Material and Methods section (Table 2). We found only four out of $91 \mathrm{D}$. hansenii strains that did not produce 1,3-pentadiene (NP, non-producers), and therefore nearly $96 \%$ of the strains of this yeast were able to produce this volatile compound.

Table 2. Sensorial results for 1,3-pentadiene producing and non-producing yeast species and strains. PCR amplification with specific primers for the differentiation between 1,3-pentadiene producers and non- producers.

\begin{tabular}{|c|c|c|}
\hline Species/ Strains & 1,3-Pentadiene Production & $\begin{array}{l}\text { Amplification with Primers } \\
\text { FDC1_Dh_Pentadien and } \\
\text { FDC1_Dh_Full_Rv }\end{array}$ \\
\hline $\begin{array}{c}\text { Debaryomyces hansenii } \\
\text { CECT11369 }{ }^{\mathrm{T}} \text {, CECT10026, CECT10352, CECT10378, } \\
\text { CBS1102, CYC1265, CYC1307, Es 4, J-01, J-09, J-11, J-15, } \\
\text { J-16, J-17, CH2, Pr11, Pr13, EPEC1.3, EPEC4, E.2, 29C1.2, } \\
\text { 29Inf1, V1.1, V1.2, V1.3, V1.4, V1.6, V1.7, V1.8, V1.9, } \\
\text { V1.10, V2.2, V2.4, V.2.5, V2.6, V2.7, V2.8, V2.10, V3.1, } \\
\text { V3.3, V3.4, V3.5, V3.6, V3.7, V3.8, V3.9, V3.10, A4.1, A4.2, } \\
\text { A5.1, A5.2, A8.1, A8.2, ent 1, ent 2, ent 9, ent 50.3,ent 56, } \\
\text { ent 64.1, ent 64.5, ent 64.6, ent 81.1, ent 81.2, ent 15, ent 19, } \\
\text { ent 24, ent 55, ent 63, ent 65, Rec1.1, Rec1.3, Rec2.3, } \\
\text { Rec2.4, Rec9.1, Rec9.2, Rec11.5, Rec13.1, Rec13.3, ent 23, } \\
\text { ent 25, ent 28, ent 95.1, ent 96.1, ent 102.1, ent 102.2, ent }\end{array}$ & + & + \\
\hline $\begin{array}{c}\text { Debaryomyces hansenii } \\
\text { CECT10517, CBS1792, J-12, Pr5 }\end{array}$ & - & - \\
\hline \multicolumn{3}{|l|}{ Other yeast species } \\
\hline $\begin{array}{c}\text { Debaryomyces fabryi } \mathrm{CECT} 11370^{\mathrm{T}}, \mathrm{CECT} 11365, \mathrm{CBS} \\
\text { 6066. Debaryomyces subglobosus } \mathrm{CBS}^{\mathrm{T}} 1796^{\mathrm{T}}, \mathrm{CBS} 792 \\
\text { Saccharomyces cerevisiae } \mathrm{ATCC} 754, \mathrm{YAA} 1, \\
\text { Wickerhamomyces anomalus } \mathrm{CECT} 1114^{\mathrm{T}}, \mathrm{CECT} 10320 \\
\text { Zygosaccharomyces rouxii } \mathrm{CECT} 1232^{\mathrm{T}}, \mathrm{Bch}, \mathrm{T} 2 \mathrm{R}\end{array}$ & + & - \\
\hline 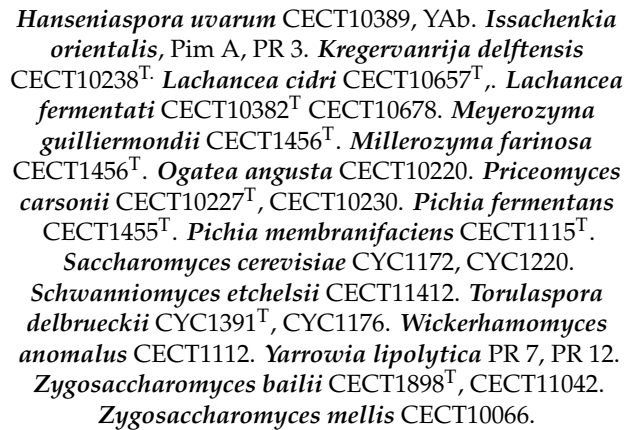 & - & - \\
\hline
\end{tabular}


Next, to achieve our goal of obtaining specific primers for the detection of $D$. hansenii strains producing 1,3-pentadiene, we designed a primer pair based on a S. cerevisiae FCD1 gene sequence to amplify putative homologous gene from $D$. hansenii gDNA $[29,30]$. The amplified region presents a sequence identity of $66 \%$ with the $F D C 1$ gene of $S$. cerevisiae. The best result for the amplification of the $F D C D h$ region was obtained after 30 cycles and with an annealing temperature of $59^{\circ} \mathrm{C}$. A single fragment of about $1542 \mathrm{bp}$ was amplified from all of the D. hansenii strains. By analysing these sequences we observed nucleotide polymorphism of the FDC1Dh gene between 1,3-pentadiene producer $(\mathrm{P})$ and non-producer (NP) strains (see Supplementary Material, Figure S2). Many nucleotide differences were related to amino acid changes (Table 3). Additionally, and most importantly, all NP strains contain at least one deletion in the nucleotide sequence of the FDC1Dh gene (Table 3). Specifically, the deletion of adenine or guanine in position 383 alters the reading frame and consequently, it would be responsible for a premature STOP codon. Only one NP strain, PR5, had two more deletions in the positions 281 and 1234, the first of them being responsible for an alteration of the reading frame and a premature STOP (see asterisks in Figure S2).

Table 3. Nucleotide polymorphisms in gene FDC1Dh that produce amino acid changes in the putative protein sequence. The numbers indicate the nucleotides positions in the gene.

\begin{tabular}{|c|c|c|c|c|c|c|c|c|c|c|}
\hline \multirow{2}{*}{ Nucleotide } & \multirow{2}{*}{$\begin{array}{l}127 \\
\text { G-A }\end{array}$} & \multirow{2}{*}{$\begin{array}{l}145 \\
\mathrm{C}-\mathrm{T}\end{array}$} & \multirow{2}{*}{$\begin{array}{l}156 \\
\text { A-T }\end{array}$} & \multirow{2}{*}{$\begin{array}{c}281 \\
*\end{array}$} & \multirow{2}{*}{$\begin{array}{l}328 \\
\text { A-G }\end{array}$} & \multirow{2}{*}{$\begin{array}{l}362 \\
\text { T-C }\end{array}$} & \multirow{2}{*}{$\begin{array}{l}367 \\
\text { C-A }\end{array}$} & \multicolumn{2}{|c|}{383} & \multirow{2}{*}{$\begin{array}{r}458 \\
\text { A-C }\end{array}$} \\
\hline & & & & & & & & G-A & * & \\
\hline \multicolumn{11}{|c|}{ D. hansenii 1,3-pentadiene producer strains } \\
\hline CECT 10352 & & + & & & & & & + & & \\
\hline CECT 10386 & & & + & & + & + & + & & & + \\
\hline $\mathrm{CH} 2$ & & & + & & + & + & + & & & + \\
\hline \multicolumn{11}{|c|}{ D. hansenii 1,3-pentadiene no producer strains } \\
\hline CECT 10517 & + & & + & & + & + & + & & + & + \\
\hline CBS 1792 & + & & + & & + & + & + & & + & + \\
\hline $\mathrm{J}-12$ & + & & + & & + & + & + & & + & + \\
\hline PR 5 & + & & + & + & + & + & + & & + & + \\
\hline Nucleotide & 733 & 775 & 798 & 1127 & 1183 & 1234 & 1251 & 1329 & 1389 & 1434 \\
\hline \multicolumn{11}{|c|}{ D. hansenii 1,3-pentadiene producer strains } \\
\hline CECT 10386 & & + & + & + & & & + & + & + & \\
\hline $\mathrm{CH} 2$ & & + & + & & + & & & & & \\
\hline EPEC 1.3 & + & & & + & & & + & + & + & + \\
\hline \multicolumn{11}{|c|}{ D. hansenii 1,3-pentadiene no producer strains } \\
\hline CECT 10517 & & + & + & + & & & + & + & + & + \\
\hline CBS 1792 & & + & + & + & & + & + & + & + & + \\
\hline $\mathrm{J}-12$ & & + & + & + & & & + & + & + & + \\
\hline PR 5 & & + & + & + & & + & + & + & + & + \\
\hline
\end{tabular}

+ , Substitution in amino acid; ${ }^{*}$,Nucleotide deletion.

As mentioned, one of the objectives of this work was to develop a simple method for differentiating P and NP strains of D. hansenii by PCR. For this, an FDC1_Dh_Pentadien degenerated primer was designed, based on the sequences of the FDC1Dh gene of the strains, as described in the Material and Methods section. It comprises the position 127 where a base change was detected in P and NP strains. The primer also contains a $\mathrm{Y}$ in position 125 that hybridises with $\mathrm{C}$ or $\mathrm{T}$ present in the sequence of $\mathrm{P}$ or NP strains, respectively (see Supplementary Material, Figure S2).

The specificity of the primers and the PCR protocol developed was tested on DNA templates obtained from yeast strains listed in Supplementary Material, Table S1. All P strains of D. hansenii gave a positive result with clear amplicons of $130 \mathrm{bp}$, whereas no amplification was found in NP strains (Figure 1). The rest of the yeast species included in the study showed no amplification, although they were 1,3-pentadiene producing strains (Table 1), supporting the specificity of developed PCR assay for D. hansenii strains. 


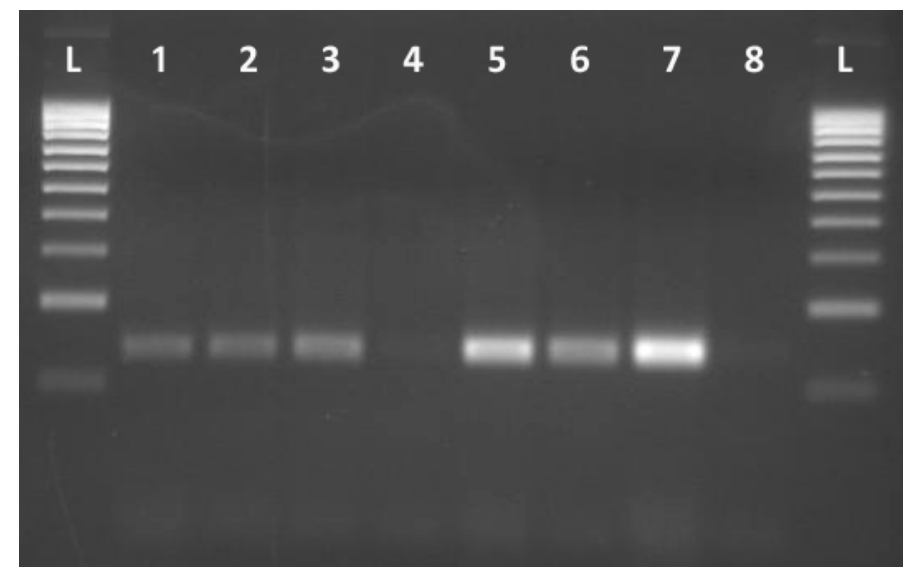

Figure 1. PCR amplification result obtained with primer pair Figure 1. Dh_Full_Rv. L: 100bp ladder. Lines 1-3, 5-7: Debaryomyces hansenii 1,3-pentadiene producer strains: CECT 11369T, Es4, EPEC 1.3, CECT 10352, CECT 10378, CH2, respectively. Line 4: D.hansenii 1,3-pentadiene no producer strain: J-12; Lane 8: Negative control.

\section{Discussion}

Debaryomyces hansenii shows a dual role in the food industry. It has different biotechnological applications, but it is also capable of spoiling certain products. Among the positive aspects, the yeast is considered a promising alternative to chemical fungicides used in agriculture and several strains have been proposed as biological control agents [17-20]. However, if potentially spoiling strains are used, such as those that degrade sorbates, the yeasts present on the fruits or vegetables could remain in the final products obtained [37-39]. Taking into account that the decarboxylation of sorbic acid is not a property of the yeast species but of the strain [40], the selection of strains that do not produce unpleasant "petroleum-like"off-odours would be of importance for quality and safety reasons. According to the International Chemical Safety Card (CAS No. 504-60-9), a low exposure (concentrations) of 1,3-pentadiene does not have an adverse effect on humans. Nevertheless, the problem is not only the production of a compound with an offensive odour but the fact that the antimicrobial action of the sorbates disappears and other undesirable fungi or bacteria can grow on the food.

Table 2 shows that the production of volatile 1,3-pentadiene is a common feature in the D. hansenii strains studied. Under the study conditions, a conversion of $45 \%$ of the sorbate into 1,3-pentadiene was measured by chromatography in $D$. hansenii (data not shown). The ability to produce 1,3-pentadiene is a strain characteristic, surprisingly nearly $96 \%$ of $91 \mathrm{D}$. hansenii strains analysed were able to produce this compound. Thus, many strains of $D$. hansenii can cause spoilage. Given that both methods, chromatographic and sensorial, need isolation and cultivation as well as another subsequent cultivation for four days with sorbates, a search for the differences between strains was conducted to develop a fast and accurate molecular method. Based on the PAD1 sequence, we previously developed a molecular method for the rapid detection of $D$. hansenii species [41]. However, when beginning this work we did not find differences in the PAD1 sequence between (P) and (NP) strains (data not shown). We thus focused our study on the $F D C 1$ gene. In this work, we describe for the first time a $D$. hansenii putative homologue sequence of the S. cerevisiae FCD1/YDR539W gene [42] related to the decarboxylation of sorbates. We developed a PCR protocol based on the differences in the $F D C 1$ sequence between $(\mathrm{P})$ and (NP) strains. The primers FDC1_Dh_Pentadien and FDC1_Dh_Full_Rv developed in this assay produce a clear single fragment of $130 \mathrm{bp}$ in all (P) D. hansenii strains tested (Table 2), and no false negatives were detected. Additionally, no false positives were found in the other 21 species included in the study. For the industry and control laboratories, this method is easier, quicker and less tedious than the sensorial method, as well as less expensive than the chromatographic method. A $24 \mathrm{~h}$ culture, 
instead of four days, is the time required by the PCR method to differentiate between $D$. hansenii 1,3-pentadiene producer strains and non-producer strains.

Supplementary Materials: The following are available online at http://www.mdpi.com/2304-8158/9/2/162/s1, Figure. S1: Gas chromatogram (above) and mass spectra (below) from the headspace gas of a suspension in YMB of pure 1,3-pentadiene (A) and from the head gas of D. hansenii CECT 11369T cultured on YMB with $0.75 \mathrm{~g} / \mathrm{l}$ potassium sorbate (B), Figure. S2: Part of the FDC1Dh nucleotide alignment in selected strains of D. hansenii including the most significant base changes. In blue, the producing strains of 1,3-pentadiene and in orange, the non-producing strains. In red, the different bases are highlighted and framed with a black rectangle. The stars show where there is nucleotide deletion. The black numbers indicate the position of each nucleotide within the gene, Table S1: Yeast species and strains used in this study and origin.

Author Contributions: P.W. and E.-M.R. performed the experiments. P.W. and M.-I.d.S. wrote the paper. M.-I.d.S. conceived and designed the experiments All authors have read and agreed to the published version of the manuscript.

Funding: This work was supported in part by the projects from the Ministry of Economy and Competitiveness (RT2018-0975593-B-C2). Research by Eva Rivas has been supported by a PICATA predoctoral fellowship (CEI Campus Moncloa, UCM-UPM, Madrid, Spain).

Acknowledgments: We would like to thank Nour Kayali and Cristina Gutiérrez for the chromatographic analysis carried out at the Mass Spectrometry Centre of the Complutense University (UCM) and Bill Newton from linguistic department of UCM.

Conflicts of Interest: The authors declare no conflict of interest.

\section{References}

1. Dolci, P.; Barmaz, A.; Zenato, S.; Pramotton, R.; Alessandria, V.; Cocolin, L.; Rantsiou, K.; Ambrosoli, R. Maturing dynamics of surface microflora in Fontina PDO cheese studied by culture-dependent and -independent methods. J. Appl. Microbiol. 2009, 106, 278-287. [CrossRef] [PubMed]

2. Padilla, B.; Manzanares, P.; Belloch, C. Yeast species and genetic heterogeneity within Debaryomyces hansenii along the ripening process of traditional ewes' and goats' cheeses. Food Microbiol. 2014, 38, 160-166. [CrossRef]

3. Petersen, K.M.; Westall, S.; Jespersen, L. Microbial succession of Debaryomyces hansenii strains during the production of Danish surfaced-ripened cheeses. J. Dairy Sci. 2002, 85, 478-486. [CrossRef]

4. Rai, A.K.; Pandey, A.; Sahoo, D. Biotechnological potential of yeasts in functional food industry. Trends Food Sci. Technol. 2019, 83, 129-137. [CrossRef]

5. Deák, T. Handbook of Food Spoilage Yeasts, 2nd ed.; CRC Press: Boca Ratón, FL, USA, 2008.

6. Hernández, A.; Pérez-Nevado, F.; Ruiz-Moyano, S.; Serradilla, M.J.; Villalobos, M.C.; Martín, A.; Córdoba, M.G. Spoilage yeasts: What are the sources of contamination of foods and beverages? Int. J. Food Microbiol. 2018, 286, 98-110. [CrossRef] [PubMed]

7. Rivas, E.M. Interacción Sorbatos-Levaduras en Alimentos: Modelización de su Efecto en Medio Sólido, Biología Molecular y Detección de su Transformación en 1, 3-Pentadieno por MWIR; Universidad Complutense de Madrid: Madrid, Spain, 2017.

8. Loureiro, V.; Querol, A. The prevalence and control of spoilage yeasts in foods and beverages. Trends Food Sci. Technol. 1999, 10, 356-365. [CrossRef]

9. Marth, E.H.; Capp, C.M.; Hasenzahl, L.; Jackson, H.W.; Hussong, R.V. Degradation of Potassium Sorbate by Penicillium Species. J. Dairy Sci. 1966, 49, 1197-1205. [CrossRef]

10. Sensidoni, A.; Rondinini, G.; Peressini, D.; Maifreni, M.; Bortolomeazzi, R. Presence of an off-flavour associated with the use of sorbates in cheese and margarine. Ital. J. Food Sci. 1994, 6, 237-242.

11. Casas, E.; de Ancos, B.; Valderrama, M.J.; Canob, P.; Peinado, J.M. Pentadiene production from potassium sorbate by osmotolerant yeasts. Int. J. Food Microbiol. 2004, 94, 93-96. [CrossRef]

12. Casas, E.; Valderrama, M.J.; Peinado, J.M. Spoilage of marzipan products by an osmotolerant yeast. Adv. Food Sci. 1996, 18, 56-60.

13. Quirós, M.; Martorell, P.; Querol, A.; Barrio, E.; Peinado, J.M.; De Silóniz, M.I. Four new Candida cretensis strains isolated from Spanish fermented sausages (chorizo): Taxonomic and phylogenetic implications. FEMS Yeast Res. 2008, 8, 485-491. [CrossRef] [PubMed] 
14. Wrent, P.; Rivas, E.M.; Gil de Prado, E.; Peinado, J.M.; de Silóniz, M.I. Debaryomyces. In Encyclopedia of Food Microbiology, 2nd ed.; Batt, C.A., Tortorello, M.L., Eds.; Elsevier Ltd., Academic Press: Oxford, UK, 2014; Volume 1, pp. 563-570.

15. Andrade, M.J.; Cordoba, J.J.; Casado, E.M.; Cordoba, M.G.; Rodriguez, M. Effect of selected strains of Debaryomyces hansenii on the volatile compound production of dry fermented sausage "salchichón". Meat Sci. 2010, 85, 256-264. [CrossRef] [PubMed]

16. Ramos-Moreno, L.; Ruiz-Castilla, F.J.; Bravo, C.; Martínez, E.; Menéndez, M.; Dios-Palomares, R.; Ramos, J. Inoculation with a terroir selected Debaryomyces hansenii strain changes physico-chemical characteristics of Iberian cured pork loin. Meat Sci. 2019, 157, 107875. [CrossRef] [PubMed]

17. Gil-Serna, J.; Patiño, B.; Cortés, L.; González-Jaén, M.T.; Vázquez, C. Mechanisms involved in reduction of ochratoxin A produced by Aspergillus westerdijkiae using Debaryomyces hansenii CYC 1244. Int. J. Food Microbiol. 2011, 151, 113-118. [CrossRef]

18. Chalutz, E.; Wilson, C.L. Postharvest biocontrol of green and blue mold and sour rot of citrus fruit by Debaryomyces hansenii. Plant Dis. 1990, 74, 134-137. [CrossRef]

19. Liu, S.-Q.; Tsao, M. Biocontrol of dairy moulds by antagonistic dairy yeast Debaryomyces hansenii in yoghurt and cheese at elevated temperatures. Food Control 2009, 20, 852-855. [CrossRef]

20. Czarnecka, M.; Żarowska, B.; Połomska, X.; Restuccia, C.; Cirvilleri, G. Role of biocontrol yeasts Debaryomyces hansenii and Wickerhamomyces anomalus in plants' defence mechanisms against Monilinia fructicola in apple fruits. Food Microbiol. 2019, 83, 1-8. [CrossRef]

21. Liewen, M.B.; Marth, E.H. Growth and inhibition of microorganisms in the presence of sorbic acid: A review. J. Food Prot. 1985, 48, 364-375. [CrossRef]

22. Pinches, S.; Apps, P. Production in food of 1,3-pentadiene and styrene by Trichoderma species. Int. J. Food Microbiol. 2007, 116, 182-185. [CrossRef]

23. Nieminen, T.; Neubauer, P.; Sivela, S.; Vatamo, S.; Silfverberg, P.; Salkinojasalonen, M. Volatile compounds produced by fungi grown in strawberry jam. LWT Food Sci. Technol. 2008, 41, 2051-2056. [CrossRef]

24. Rivas, E.M.; Maldonado, M.; Diezma, B.; Wrent, P.; Peinado, J.; de Silóniz, M.I.; Vergara, G.; García Hierro, J.; Robla, J.I.; Barreiro, P. Detection of Biological CO2 and 1,3-Pentadiene Using Non-refrigerated Low-Cost MWIR Detectors. Food Anal. Methods 2016, 9, 1451-1460. [CrossRef]

25. Plumridge, A.; Stratford, M.; Lowe, K.C.; Archer, D.B. The weak-acid preservative sorbic acid is decarboxylated and detoxified by a phenylacrylic acid decarboxylase, PadA1, in the spoilage mold Aspergillus niger. Appl. Environ. Microbiol 2008, 74, 550-552. [CrossRef] [PubMed]

26. Stratford, M.; Plumridge, A.; Archer, D.B. Decarboxylation of Sorbic Acid by Spoilage Yeasts Is Associated with the PAD1 Gene. Appl. Environ. Microbiol. 2007, 73, 6534-6542. [CrossRef] [PubMed]

27. Goodey, A.R.; Tubb, R.S. Genetic and Biochemical Analysis of the Ability of Saccharomyces cerevisiae to Decarboxylate Cinnamic Acids. Microbiology 1982, 128, 2615-2620. [CrossRef]

28. Plumridge, A.; Melin, P.; Stratford, M.; Novodvorska, M.; Shunburne, L.; Dyer, P.S.; Roubos, J.A.; Menke, H.; Stark, J.; Stam, H. The decarboxylation of the weak-acid preservative, sorbic acid, is encoded by linked genes in Aspergillus spp. Fungal Genet. Biol. 2010, 47, 683-692. [CrossRef]

29. Mukai, N.; Masaki, K.; Fujii, T.; Kawamukai, M.; Iefuji, H. PAD1 and FDC1 are essential for the decarboxylation of phenylacrylic acids in Saccharomyces cerevisiae. J. Biosci. Bioeng. 2010, 109, 564-569. [CrossRef]

30. Mukai, N.; Masaki, K.; Fujii, T.; Iefuji, H. Single nucleotide polymorphisms of PAD1 and FDC1 show a positive relationship with ferulic acid decarboxylation ability among industrial yeasts used in alcoholic beverage production. J. Biosci. Bioeng. 2014, 118, 50-55. [CrossRef]

31. Camacho, C.; Coulouris, G.; Avagyan, V.; Ma, N.; Papadopoulos, J.; Bealer, K.; Madden, T.L. BLAST+: Architecture and applications. BMC Bioinform. 2009, 10, 421. [CrossRef]

32. Lõoke, M.; Kristjuhan, K.; Kristjuhan, A. Extraction of genomic DNA from yeasts for PCR-based applications. BioTechniques 2011, 50, 325-328. [CrossRef]

33. ApE-A plasmid Editor. Available online: http://www.biology.utah.edu/jorgensen/wayned/ape/ (accessed on 1 June 2017).

34. Sievers, F.; Wilm, A.; Dineen, D.; Gibson, T.J.; Karplus, K.; Li, W.; Lopez, R.; McWilliam, H.; Remmert, M.; Soding, J.; et al. Fast, scalable generation of high-quality protein multiple sequence alignments using Clustal Omega. Mol. Syst. Biol. 2011, 7, 539. [CrossRef] 
35. Robert, X.; Gouet, P. Deciphering key features in protein structures with the new ENDscript server. Nucleic Acids Res. 2014, 42, W320-W324. [CrossRef]

36. Casas, E.; Valderrama, M.J.; Peinado, J.M. Simplified Test for the Rapid Detection of Dangerous Yeasts and Filamentous Fungi in Marzipan Products. In Improved Tradicional Foods for the Next Century; Toldrá, F., Ramón, D., Navarro, J.L., Eds.; Gráficas Barrastil: Valencia, Spain, 1999; pp. 304-307.

37. Núñez, F.; Lara, M.S.; Peromingo, B.; Delgado, J.; Sánchez-Montero, L.; Andrade, M.J. Selection and evaluation of Debaryomyces hansenii isolates as potential bioprotective agents against toxigenic penicillia in dry-fermented sausages. Food Microbiol. 2015, 46, 114-120. [CrossRef]

38. Kinay, P.; Yildiz, M. The shelf life and effectiveness of granular formulations of Metschnikowia pulcherrima and Pichia guilliermondii yeast isolates that control postharvest decay of citrus fruit. Biol. Control 2008, 45, 433-440. [CrossRef]

39. Wrent, P.; Rivas, E.M.; Gil de Prado, E.; Peinado, J.M.; de Silóniz, M.I. Assessment of the factors contributing to the growth or spoilage of Meyerozyma guilliermondii in organic yogurt: Comparison of methods for strain differentiation. Microorganisms 2015, 3, 428-440. [CrossRef]

40. Wrent, P.; Rivas, E.M.; Peinado, J.M.; de Silóniz, M.I. Strain typing of Zygosaccharomyces yeast species using a single molecular method based on polymorphism of the intergenic spacer region (IGS). Int. J. Food Microbiol. 2010, 142, 89-96. [CrossRef]

41. Wrent, P.; Rivas, E.M.; Gil de Prado, E.; Peinado, J.M.; de Silóniz, M.I. Development of species-specific primers for rapid identification of Debaryomyces hansenii. Int. J. Food Microbiol. 2015, 193, 109-113. [CrossRef]

42. Saccharomyces genome database. Available online: http://www.yeastgenome.org (accessed on 1 June 2017).

(C) 2020 by the authors. Licensee MDPI, Basel, Switzerland. This article is an open access article distributed under the terms and conditions of the Creative Commons Attribution (CC BY) license (http://creativecommons.org/licenses/by/4.0/). 